\title{
OPEN In situ activation graphitization to fabricate hierarchical porous graphitic carbon for supercapacitor
}

\author{
Yanling Zhao ${ }^{1 \bowtie}$ \& Xiaohua Zhang ${ }^{2 \bowtie}$
}

In situ activation-graphitization method based on the atomically dispersed $\mathrm{K}$ and Fe in organic salts is developed to synthesize hierarchical porous graphitic carbon by directly pyrolysis potassium citrate and iron citrate. Moreover, $\left(\mathrm{NH}_{4}\right)_{2} \mathrm{C}_{2} \mathrm{O}_{4}$ is also employed as both $\mathrm{N}$ dopant and porogen to open up internal structure and regulate pore structure. The inside-out activation leads to the homogeneous reaction and interconnected hierarchical porous structure with few dead pores. Accompanied by high specific surface area, appropriate pore distribution, good conductivity, and N/O functional groups, the sample exhibits high capacitance of $322.6 \mathrm{~F} \mathrm{~g}^{-1}$ at $0.5 \mathrm{~A} \mathrm{~g}^{-1}$, good rate capability, and excellent cycling stability with $101.5 \%$ capacitance retention after 15,000 cycles. The supercapacitor shows an energy density of $21.3 \mathrm{~W} \mathrm{~h} \mathrm{~kg}{ }^{-1}$ at $456.7 \mathrm{~W} \mathrm{~kg}^{-1}$ in $1 \mathrm{M} \mathrm{Na}_{2} \mathrm{SO}_{4}$. Easy synthesis, cost-effective, and environmentally benign, the work provides a promising strategy to produce hierarchical porous graphitic carbon applied in energy storage.

Energy storage devices play a pivotal role in the development of clean and sustainable energy, and they have been widely applied in electric vehicles, solar energy, wind power industry and so on ${ }^{1,2}$. Supercapacitors represent one of the promising energy storage technologies owing to their high power density, fast charge-discharge rate, and long cyclic stability, which are interesting for various clean-energy device systems $s^{3,4}$. Porous carbon (PC) materials offer numerous advantages for energy storage and show excellent electrochemical performances in supercapacitors, based on their large specific surface area $\left(S_{\mathrm{BET}}\right)$, hierarchical porous structure, relatively good conductivity, and excellent chemical and mechanical stability ${ }^{5,6}$. Specifically, large $S_{\mathrm{BET}}$ can provide numerous active sides for charge storage; hierarchical porous structure can simultaneously serve as ion-buffering reservoirs (macropores), act as rapid ion transfer channels (mesopores), and provide abundant locations for ions accumulation (micropores); good conductivity can greatly enhance electron transport kinetics ${ }^{7}$. However, pore structure and electrical conductivity of carbon materials have a competitive relationship. A highly porous structure usually lead to poor electrical conductivity owing to excessive macropores and mesopores ${ }^{8}$. In contrast, good electrical conductivity is usually linked with a high graphitization degree, giving rise to undeveloped pore structure and a small $S_{\mathrm{BET}}$, which are unfavorable for ions transport and charge accommodation. On account of this, a rational balanced relationship between pore structure and electrical conductivity is of great significance to maximize the electrochemical performances.

Porous carbon, especially activated carbon, is often prepared by pyrolyzing carbon-rich organic materials with activating agents to develop hierarchical porosity and enhance $S_{\mathrm{BET}}{ }^{9}$. However, the graphitic structure is not desirable after chemical activation. Catalytic graphitization with transition metals as catalyst is an effective way to promote the formation of graphitic structure. Previous researches indicate that the combination of chemical activation and catalytic graphitization is an effective way to simultaneously improve pore structure and graphitization degree. For example, carbon precursors are treated with two different catalysts, which are used for chemical activation (pore-forming reagents: $\mathrm{KOH}, \mathrm{ZnCl}_{2}$, or $\mathrm{K}_{2} \mathrm{CO}_{3}$ ) and catalytic graphitization (metals salts containing $\mathrm{Fe}, \mathrm{Co}$, or $\mathrm{Ni})^{8}$. Chang et al. fabricated hierarchical porous carbon by metal ion pretreatment and a two-step post-activation ${ }^{10}$. The presence of catalyst $\mathrm{Co}\left(\mathrm{NO}_{3}\right)_{2}$ is able to balance the reduced graphitization caused by activation. Many porous graphitic carbon (PGC) materials can also be synthesized by one-step carbonization with $\mathrm{FeCl}_{3}$ and $\mathrm{ZnCl}_{2}$ as graphitization catalyst and chemical activator, respectively ${ }^{11,12}$. Although more effective, the majority of activating agents, such as $\mathrm{KOH}, \mathrm{ZnCl}_{2}$, and $\mathrm{H}_{3} \mathrm{PO}_{4}$, are highly corrosive and harmful, which cause serious corrosion of equipment and environmental problems. To this end, it is highly desirable to develop facile

${ }^{1}$ College of Medical Imaging, Shanxi Medical University, Taiyuan 030001, China. ${ }^{2}$ College of Materials Science and Engineering, Taiyuan University of Science and Technology, Taiyuan 030024, China. ${ }^{\varpi}$ email: yxzyl1998@126.com; xiaohuaz08@163.com 

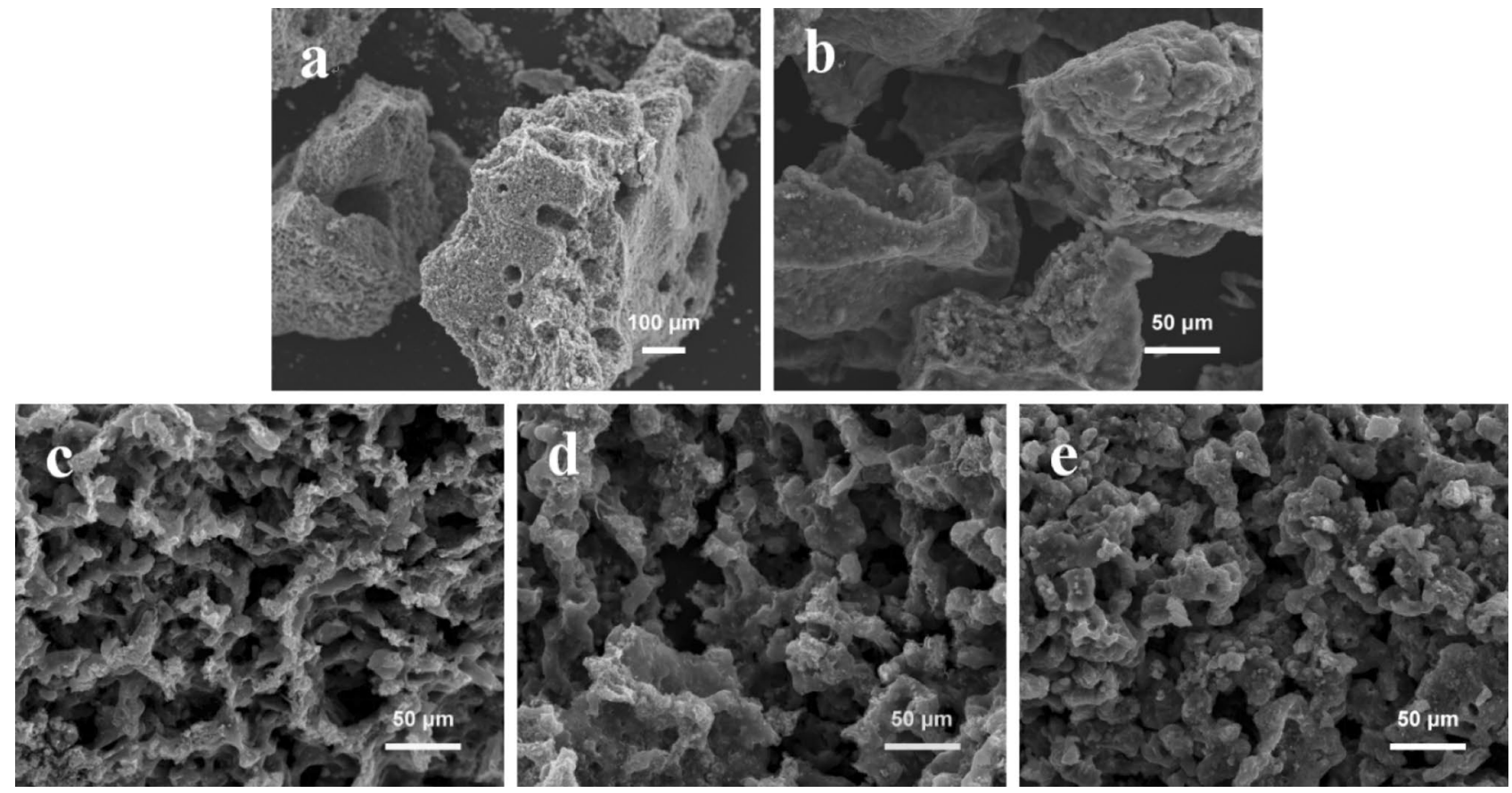

Figure 1. SEM images of (a) PC-750, (b) PGC-750, (c) HPGC-700, (d) HPGC-750, and (e) HPGC-800. Photographs compiled using Powerpoint 2019 (https://www.microsoft.com/zh-cn/microsoft-365/get-startedwith-office-2019) without changing the content of images themselves.

and eco-friendly strategy to develop hierarchical porous graphitic carbon (HPGC) with hierarchical porous structure and high graphitization degree.

Recently, carbon materials derived from organic salts (such as potassium citrate, ferric citrate, calcium gluconate) have drawn considerable attention, owing to their merits of low-cost, well-defined molecular, and facile procedures for carbonization and graphitization ${ }^{13-15}$. Besides, organic salts have atomically dispersed metal species, such as $\mathrm{K}, \mathrm{Na}, \mathrm{Ca}, \mathrm{Fe}$, and so on. These dispersed metal species can be used as self-templates, activating agents, or graphitization catalysts. For example, the polymer containing $\mathrm{K}$ can be decomposed and produces $\mathrm{K}_{2} \mathrm{CO}_{3}$ during carbonization, creating pores in carbon framework ${ }^{16}$. As for iron species, it can be reduced by carbon to form $\mathrm{Fe}_{3} \mathrm{C}$ at high temperature, which is an important intermediate product for the formation of graphitic carbon ${ }^{17}$. In previous reports, potassium citrate and iron citrate have been respectively studied as carbon source to produce carbon material for applied in supercapacitors ${ }^{18,19}$. However, they only focused on the influences of porous structure, specific surface area, or electron conductivity on the electrochemical performances of carbon materials, without considering the competitive relationship between pore structure and electrical conductivity. In this paper, both potassium citrate and ferric citrate were used as carbon sources. Taking advantages of these two different organic salts, in situ activation-graphitization can be achieved. The obtained materials can balance the relationship between pore structure and graphitization degree. Moreover, we employed $\left(\mathrm{NH}_{4}\right)_{2} \mathrm{C}_{2} \mathrm{O}_{4}$ as pore-forming agent and nitrogen precursor to increase the active surface area and provide additional pseudocapacitance ${ }^{20}$.

\section{Results}

Morphology and structural properties. During the high temperature treatment of potassium citrate, a certain amount of $\mathrm{K}$ compounds can be generated, such as $\mathrm{K}_{2} \mathrm{CO}_{3}$ and $\mathrm{K}_{2} \mathrm{O} . \mathrm{K}_{2} \mathrm{CO}_{3}$ acts as a crucial role in the development of micropores, which can play as an activating agent and corrode carbon skeleton $\left(\mathrm{K}_{2} \mathrm{CO}_{3}+2 \mathrm{C} \rightarrow 2 \mathrm{~K}+3 \mathrm{CO}\right)$. And the $\mathrm{K}$ vapors can intercalate into carbon materials, making swelling and disruption of carbon microstructure and creating additional porosity ${ }^{18}$. Besides, $\mathrm{Fe}_{3} \mathrm{C}$ can be formed during the thermal decomposition process of iron citrate, and it can transform amorphous carbon into graphitized carbon at high temperature. The morphology and pore geometry of the prepared carbon materials were observed by SEM images. Both PC-750 (Fig. 1a) and PGC-750 (Fig. 1b) exhibit a bulky monolithic morphology, and large pores are hard to be observed. The solid block of carbon with few macropores or mesopores is disadvantageous for ions transport and energy storage. Surprisingly, when $\left(\mathrm{NH}_{4}\right)_{2} \mathrm{C}_{2} \mathrm{O}_{4}$ is incorporated during the carbonization process, the bulk carbon particles are converted into unique, well-defined $3 \mathrm{D}$ honeycomb framework constructed by hierarchical porous carbon skeletons (Fig. 1d), showing good pore connectivity. The macropores are evenly distributed in HPGC-750, which is attributed to physical activation effect of the chemically released gases $\left(\mathrm{NH}_{3}\right.$, $\mathrm{CO}, \mathrm{CO}_{2}$ ) from $\left(\mathrm{NH}_{4}\right)_{2} \mathrm{C}_{2} \mathrm{O}_{4}$ during thermal pyrolysis. The different structures of PGC-750 and HPGC-750 indicate that the employment of $\left(\mathrm{NH}_{4}\right)_{2} \mathrm{C}_{2} \mathrm{O}_{4}$ is contributed to the formation of interconnected porous structure. Figure 1c-e manifest that carbonization temperature is the key element influence the morphologies of carbon materials. With the increase of temperature, the honeycomb structure of HPGC-T step-by-step becomes irregu- 

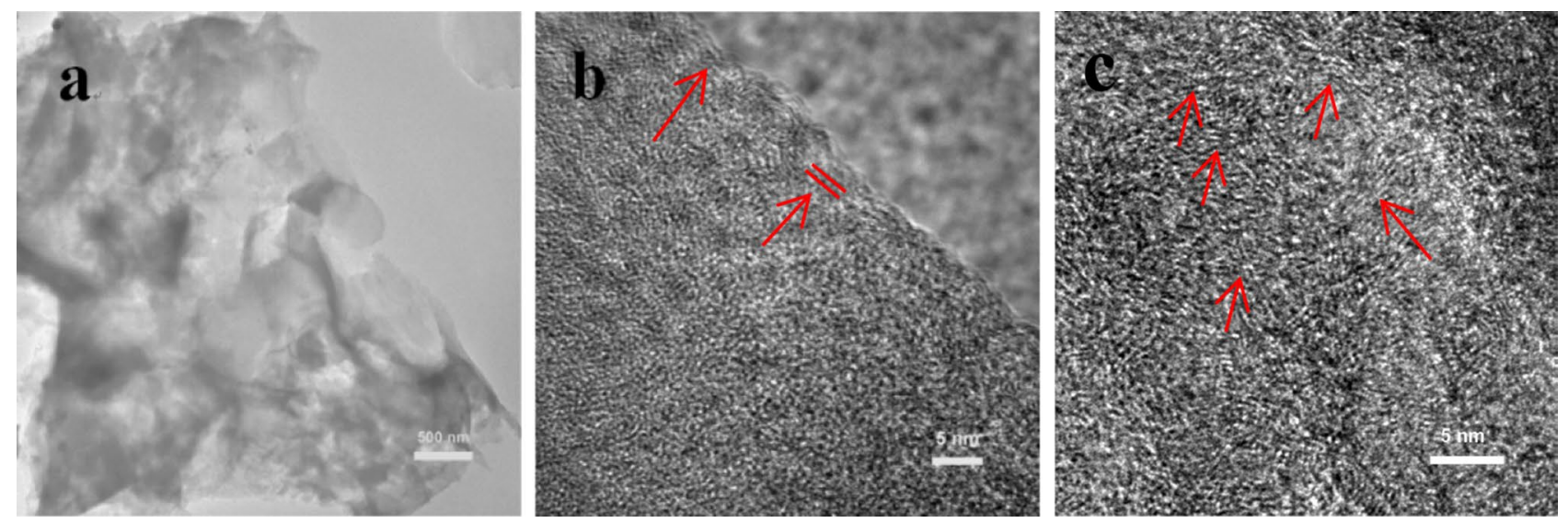

Figure 2. (a,b) TEM images of HPGC-750 under different magnifications; (c) TEM image of HPGC-800. Photographs compiled using Powerpoint 2019 (https://www.microsoft.com/zh-cn/microsoft-365/get-startedwith-office-2019) without changing the content of images themselves.
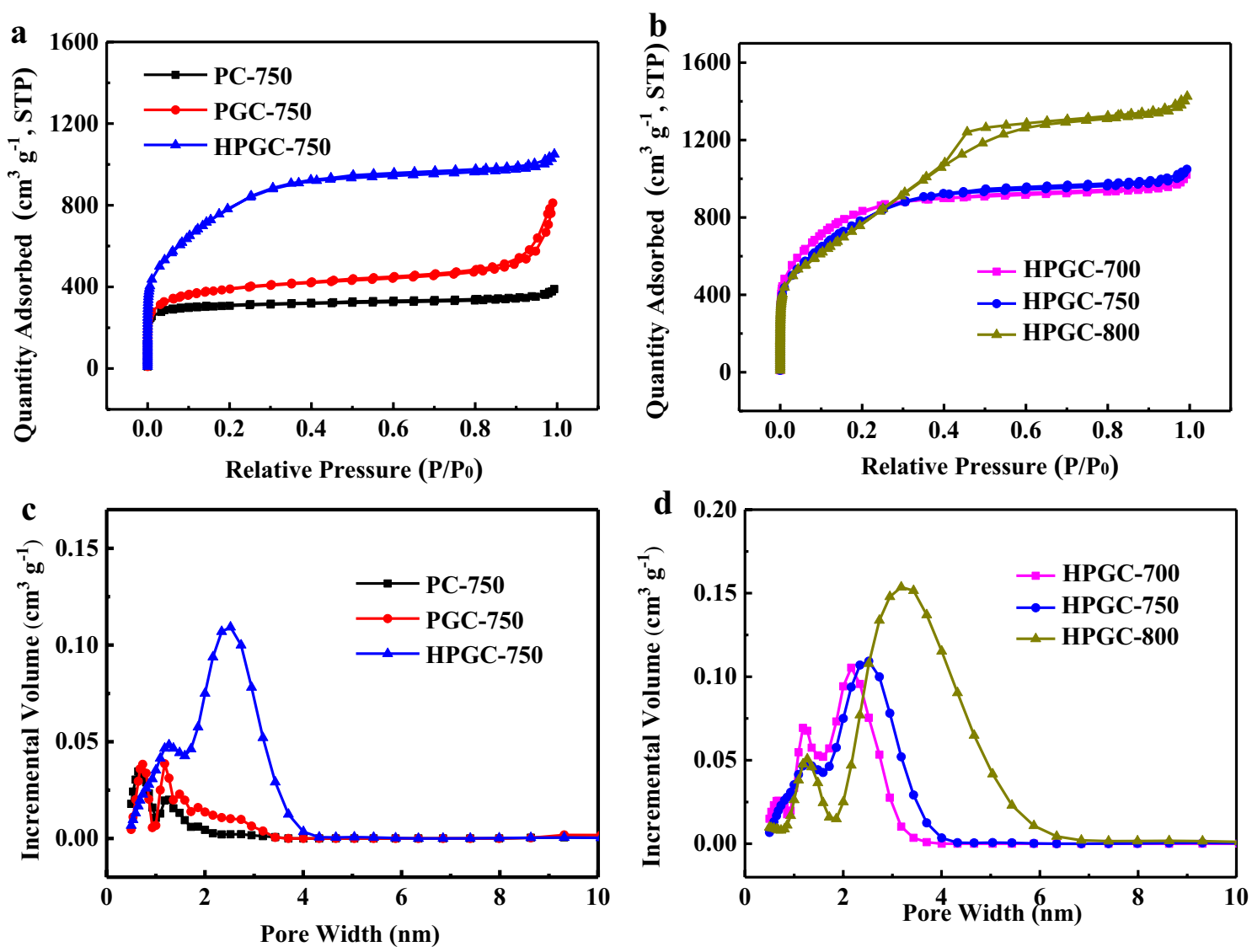

Figure 3. (a) $\mathrm{N}_{2}$ adsorption-desorption isotherms and (c) the pore size distribution curves of PC-750, PGC750, and HPGC-750; (b) $\mathrm{N}_{2}$ adsorption-desorption isotherms and (d) the pore size distribution curves of HPGC- $T$.

lar, which caused by the collapse of the carbon skeleton at high temperature ${ }^{21}$. TEM images also confirm that HPGC-750 has a honeycomb-like porous structure with macropores, mesopores (Fig. 2a) and dense micropores (Fig. 2b). The combination of macropores, mesopores, and micropores can buffer electrolyte to shorten ion diffusion distance and facilitate fast ion transport to the interior surface, providing numerous effective electrochemical sites. In Fig. 2 b, some ordered lattic fringes with the interlayers spacing of $\sim 0.34 \mathrm{~nm}$, originated from the graphitization of carbon. More ordered lattic fringes can be observed in HPGC-800 (Fig. 2c), indicating a higher content of graphitic carbon. 


\begin{tabular}{|l|l|l|l|l|l|l|}
\hline Samples & $\boldsymbol{S}_{\text {BET }}\left(\mathbf{m}^{2} \mathbf{g}^{-1}\right)$ & $\boldsymbol{S}_{\text {mic }}{ }^{\mathbf{a}}\left(\mathbf{m}^{2} \mathbf{g}^{-1}\right)$ & $\boldsymbol{S}_{\text {mes }}{ }^{\mathbf{b}}\left(\mathbf{m}^{2} \mathbf{g}^{-1}\right)$ & $V_{\text {mic }}{ }^{\mathbf{c}}\left(\mathbf{c m}^{3} \mathbf{g}^{-1}\right)$ & $\boldsymbol{V}_{\text {total }}{ }^{\mathbf{d}}\left(\mathbf{c m}^{3} \mathbf{g}^{-1}\right)$ & $\boldsymbol{D}_{\text {ap }}{ }^{\mathbf{e}}(\mathbf{n m})$ \\
\hline PC-750 & 1194.0 & 573.9 & 620.1 & 0.49 & 0.60 & 2.02 \\
\hline PGC-750 & 1445.0 & 574.0 & 871 & 0.53 & 1.25 & 3.47 \\
\hline HPGC-700 & 3118.3 & 1589.1 & 1529.2 & 1.39 & 1.58 & 2.03 \\
\hline HPGC-750 & 2973.3 & 1586.4 & 1386.9 & 1.45 & 1.62 & 2.18 \\
\hline HPGC-800 & 2951.1 & 1597.2 & 1353.9 & 1.97 & 2.21 & 2.99 \\
\hline
\end{tabular}

Table 1. Porosity properties of as-prepared carbon samples. ${ }^{\mathrm{a}}$ Micropore surface area. ${ }^{\mathrm{b}}$ Mesopore surface area. ${ }^{\mathrm{c}}$ Micropore volume. ${ }^{\mathrm{d}}$ Total pore volume. ${ }^{\mathrm{e}}$ Average pore size.

The $\mathrm{N}_{2}$ adsorption-desorption isotherm of PC-750 in Fig. 3a displays a type-I isotherm, indicating the existence of a large amount of micropores, which originate from the in-suit activation effect of potassium citrate. PGC750 shows a type-II isotherm with an increased adsorption at high relative pressure region $\left(P / P_{0}>0.9\right)$, revealing that PGC-750 consists of micropores and macropores. Obviously, when using $\left(\mathrm{NH}_{4}\right)_{2} \mathrm{C}_{2} \mathrm{O}_{4}$ as pore-forming agent, the adsorbed quantity of HPGC-750 dramatically increases and the isotherm can be classified as type-IV isotherm, which is attributed to a large number of mesopores in the sample as verified by pore size distribution curves in Fig. 3c. Mesopore can effectively minimize ion transport resistance and improve the wettability of the material $^{22}$. Detailed texture properties of the samples are summarized in Table 1 . When only potassium citrate used, PC-750 has the lowest $S_{\mathrm{BET}}$ of $1194.0 \mathrm{~m}^{2} \mathrm{~g}^{-1}$ and the smallest total pore volume $\left(V_{\text {total }}, 0.60 \mathrm{~cm}^{3} \mathrm{~g}^{-1}\right)$. With the presence of ferric citrate, $S_{\mathrm{BET}}$ and $V_{\text {total }}$ of PGC-750 increase to $1445.0 \mathrm{~cm}^{3} \mathrm{~g}^{-1}$ and $1.25 \mathrm{~cm}^{3} \mathrm{~g}^{-1}$, respectively. The distinct differences in porosity properties suggest that the presence of Fe species offer additional templates to create pores and increase $S_{\mathrm{BET}}$. Significant increase in both $S_{\mathrm{BET}}$ and $V_{\text {total }}$ have been observed in HPGC-750 because the released gases $\left(\mathrm{NH}_{3}, \mathrm{CO}, \mathrm{CO}_{2}\right.$, and $\left.\mathrm{H}_{2} \mathrm{O}\right)$ from $\left(\mathrm{NH}_{4}\right)_{2} \mathrm{C}_{2} \mathrm{O}_{4}$, which may act as pore-forming agents to create more pores ${ }^{23}$. Carbonization temperature also has a great influence on porous structure (i.e. $S_{\mathrm{BET}}$, pore size distribution, and total pore volume). As seen in Fig. 3b, HPGC-700 and HPGC-750 have the same features about isotherms, but the isotherm of HPGC- 800 has obvious change. The $S_{\text {BET }}$ of HPGC- $T$ follows the trend of HPGC-700 $\left(3118.3 \mathrm{~m}^{2} \mathrm{~g}^{-1}\right)>$ HPGC-750 $\left(2973.3 \mathrm{~m}^{2} \mathrm{~g}^{-1}\right)>$ HPGC-800 $\left(2951.1 \mathrm{~m}^{2} \mathrm{~g}^{-1}\right)$. The pore size distribution curves in Fig. 3d indicate an enlargement of pore size, especially mesoporous, as the temperature increases. The average pore size enlarges from $2.03 \mathrm{~nm}$ (HPGC-700) to $2.99 \mathrm{~nm}$ (HPGC-800). These phenomenons are caused by the collapse of carbon skeleton at higher carbonization temperature.

The graphitic structures of the prepared carbon materials were investigated by XRD and Raman. As shown in Fig. 4a, both PC-750 and PGC-750 show a broad diffraction peak $\left(2 \theta \approx 20-30^{\circ}\right)$, which is the characteristic of amorphous carbon framework. While, PGC-750 has an additional peak at $2 \theta=26.26^{\circ}$ assigned to the (002) diffraction of graphitic carbon, indicating its partly graphitic structure. Interestingly, with the presence of $\left(\mathrm{NH}_{4}\right)_{2} \mathrm{C}_{2} \mathrm{O}_{4}$, the intensity of (002) diffraction peak of HPGC-750 becomes sharper and stronger, suggesting a higher graphitization degree. Moreover, a higher intensity of peak at the low-angle scattering region indicates a high density of micropores, thus providing more active sites for charge storage. Carbonization temperature is one of the key factors affecting the graphitic structure of carbon materials. As shown in Fig. 4b, high temperature results in an increased intensity of (002) peak, which is related to the development of amorphous structure towards the graphitic structure.

Raman spectra further prove the characteristic of disorder carbon and graphitic carbon (Fig. 4c,d). All Raman spectra of samples show the well-known D-band (stemming from the disordered carbon) at around $1375 \mathrm{~cm}^{-1}$ and typical G-bond (originating from the $\mathrm{sp}^{2}$-hybridized graphitic carbon) at around $1620 \mathrm{~cm}^{-1}$. The $I_{\mathrm{G}} / I_{\mathrm{D}}$ value of carbon material can be taken as an index to reflect the graphitic degree. The $I_{\mathrm{G}} / I_{\mathrm{D}}$ values of PC-750, PGC-750, and HPGC-750 are $0.99,1.00$, and 1.02, respectively, which are significantly higher than that of commercial Norit activated carbon $\left(I_{\mathrm{G}} / I_{\mathrm{D}}=0.52\right)^{24}$. In addition, the $I_{\mathrm{G}} / I_{\mathrm{D}}$ value increases from 1.00 (HPGC-700) to 1.02 (HPGC800) with carbonization temperature increases from 700 to $800{ }^{\circ} \mathrm{C}$, which is in accordance with the XRD patterns. The appropriate coexistence of graphitic and amorphous carbon could enhance electrical conductivity, improve wettability, and increase active surface area, benefitting for capacitance improvement ${ }^{22}$.

The surface functional groups of carbon materials were investigated by FTIR spectroscopy (Figure S1). All PC-750, PGC-750, and HPGC-750 have strong and broad bands at $\sim 3435 \mathrm{~cm}^{-1}$ corresponding to the O-H stretching. The bands at $\sim 2916$ and $\sim 1639 \mathrm{~cm}^{-1}$ are ascribed to $\mathrm{C}-\mathrm{H}$ and $\mathrm{C}=\mathrm{O}$ functionalities, respectively. The band at $1389 \mathrm{~cm}^{-1}$ is attributed to either $\mathrm{C}-\mathrm{H}$ bending vibration or $\mathrm{O}-\mathrm{H}$ deformation. The bands at $1123 \mathrm{~cm}^{-1}$ can be ascribed to the $\mathrm{C}-\mathrm{O}-\mathrm{C}$ stretching vibration ${ }^{25}$. The XPS survey spectra of HPGC-750 are shown in Fig. 5. In Fig. 5a, two pronounced peaks locate at 284.8 and $\sim 533.3 \mathrm{eV}$, attributed to carbon $(\mathrm{C} 1 \mathrm{~s}, 85.10$ at $\%)$ and oxygen (O $1 \mathrm{~s}, 11.65$ at\%), respectively. And a weak peak appeared at $\sim 401.7 \mathrm{eV}$ should be attributed to $\mathrm{N} 1 \mathrm{~s}$, and the $\mathrm{N}$ content is 3.24 at\%, indicating that $\mathrm{NH}_{3}$ gas generated by pyrolysis process of $\left(\mathrm{NH}_{4}\right)_{2} \mathrm{C}_{2} \mathrm{O}_{4}$ subsequently doped into HPGC-750 to bring $\mathrm{N}$ into carbon matrix. The high-resolution of $\mathrm{C} 1 \mathrm{~s}$ spectra can be deconvoluted into four peaks (Fig. $5 \mathrm{~b})$, representing $s p^{2}$-bonded carbon $(284.5 \mathrm{eV}), s p^{3}$-bonded carbon/C-N $(285.0 \mathrm{eV}), \mathrm{C}-\mathrm{O}$ $(286.4 \mathrm{eV})$, and $\mathrm{C}=\mathrm{O} / \mathrm{C}=\mathrm{N}(288.9 \mathrm{eV})$. The deconvoluted high-resolution $\mathrm{O} 1 \mathrm{~s} \mathrm{XPS}$ spectra (Fig. 5c) exhibit five peaks centered at 530.7, 531.6, 532.7, 533.5, and $534.0 \mathrm{eV}$, corresponding to pyridone, $\mathrm{C}=\mathrm{O}, \mathrm{C}-\mathrm{OH}, \mathrm{O}-\mathrm{C}-\mathrm{O}$, and $\mathrm{O}=\mathrm{C}-\mathrm{OH}$, respectively. Four component peaks of nitrogen are found in the XPS spectra of N $1 \mathrm{~s}$ (Fig. 5d), indicating four different chemical states of nitrogen atoms in carbon network, including pyridinic-N $(398.6 \mathrm{eV})$, pyrrolic-N $(399.9 \mathrm{eV})$, graphitic-N $(400.87 \mathrm{eV})$, and quaternary- $\mathrm{N}^{+}-\mathrm{O}^{-}(402.47 \mathrm{eV})^{22,26}$, as described in Fig. 5e. Among them, pyridinic- $\mathrm{N}$ and pyrrolic- $\mathrm{N}$ are electroactive and contribute to providing pseudocapacitance, 

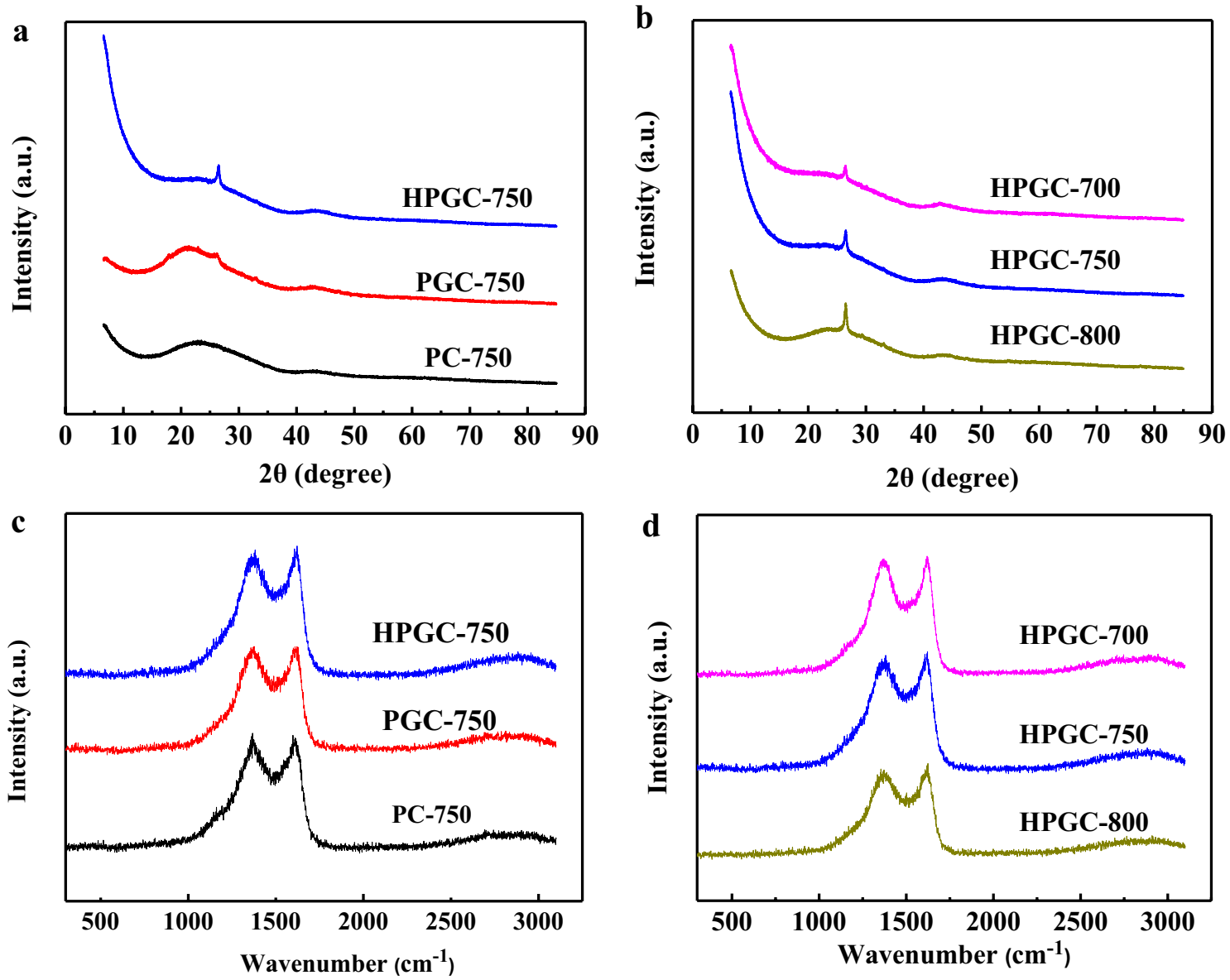

Figure 4. (a) XRD patterns and (c) Raman spectra of PC-750, PGC-750, and HPGC-750; (b) XRD patterns and (d) Raman spectra of HPGC-T.

and therefore enhanced capacitance, whereas graphitic-N can facilitate the electron transfer, improving the conductivity of carbon materials ${ }^{27}$.

Electrochemical measurements. Due to honeycomb-like hierarchical porous structure, large accessible surface area, and sufficient heteroatoms, HPGC-750 is expected to be an ideal electrode for supercapacitors. Figure 6a compares the CV curves of PC-750, PGC-750, and HPGC-750 at a current density of $10 \mathrm{mV} \mathrm{s}^{-1}$. In the case of HPGC-750, the CV curve displays the largest CV curve area, indicating the highest specific capacitance, evidencing the advantages of $3 \mathrm{D}$ honeycomb-like hierarchical porous graphitic carbon. A slight hump is also observed, which is corresponding to the redox reactions of $\mathrm{N}$ and $\mathrm{O}$ functional groups ${ }^{21,27}$. A pair of sharp peaks at the edge of -1 and $0 \mathrm{~V}$ could be ascribed to limited ion transport and adsorption in some irregular micropores with narrow bottlenecks ${ }^{28}$. HPGC-750 also has the maximum CV curve area among HPGC-T samples (Fig. 6b). Although HPGC-700 possesses the largest $S_{\mathrm{BET}}$, the relatively poor graphitization degree limits electron transfer and charge storage. Figure $6 \mathrm{c}$ shows the CV curves of HPGC-750 at various scan rates from 10 to $100 \mathrm{mV} \mathrm{s}^{-1}$. With increasing scan rate, a slight deviation from the rectangular nature of CV plots is associated with limited ions diffusion at higher scan rate.

The GCD curves of HPGC-750 are shown in Fig. 6d. The approximately symmetric triangle shapes of curves at all current densities indicate a predominantly double-layer charge storage mechanism. Figure 6e displays the specific capacitances of PC-750, GC-750, and HPGC- $T$ at different current densities. HPGC-750 has the highest capacitance of $322.6 \mathrm{~F} \mathrm{~g}^{-1}$ at $0.5 \mathrm{~A} \mathrm{~g}^{-1}$. Besides, it maintains a high capacitance of $258.4 \mathrm{~F} \mathrm{~g}^{-1}$ at an ultrahigh current density of $30 \mathrm{~A} \mathrm{~g}^{-1}$. The high capacitance of HPGC-750 could be attributed to the multiple synergistic effects: (1) hierarchical porous structure integrates the advantages of different pore structures, simultaneously providing ion-buffering reservoirs, rapid ion transfer channels, and abundant locations for ions accumulation; (2) owing to the effects of chemical activation and physical activation, HPGC-750 has a ultrahigh $S_{\mathrm{BET}}$, providing enough active sides for energy storage; (3) the coexistence of graphitic and amorphous carbon structure could enhance electrical conductivity and improve wettability, benefitting for capacitance improvement. The rate performance is a key parameter to evaluate the electrochemical performance of electrode. In hierarchical porous graphitic texture, micropores provide active sides for charge storage, macropores serve as ion-buffering reservoirs, mesopores act as ion-highways to facilitate fast ion transmission, and graphitic structure provides conductive network for rapid charge transfer. When the current density increased by 30 times, HPGC-750 and HPGC-800 achieve excellent rate capabilities of $80.1 \%$ and $79.2 \%$, respectively. The outstanding rate capability 

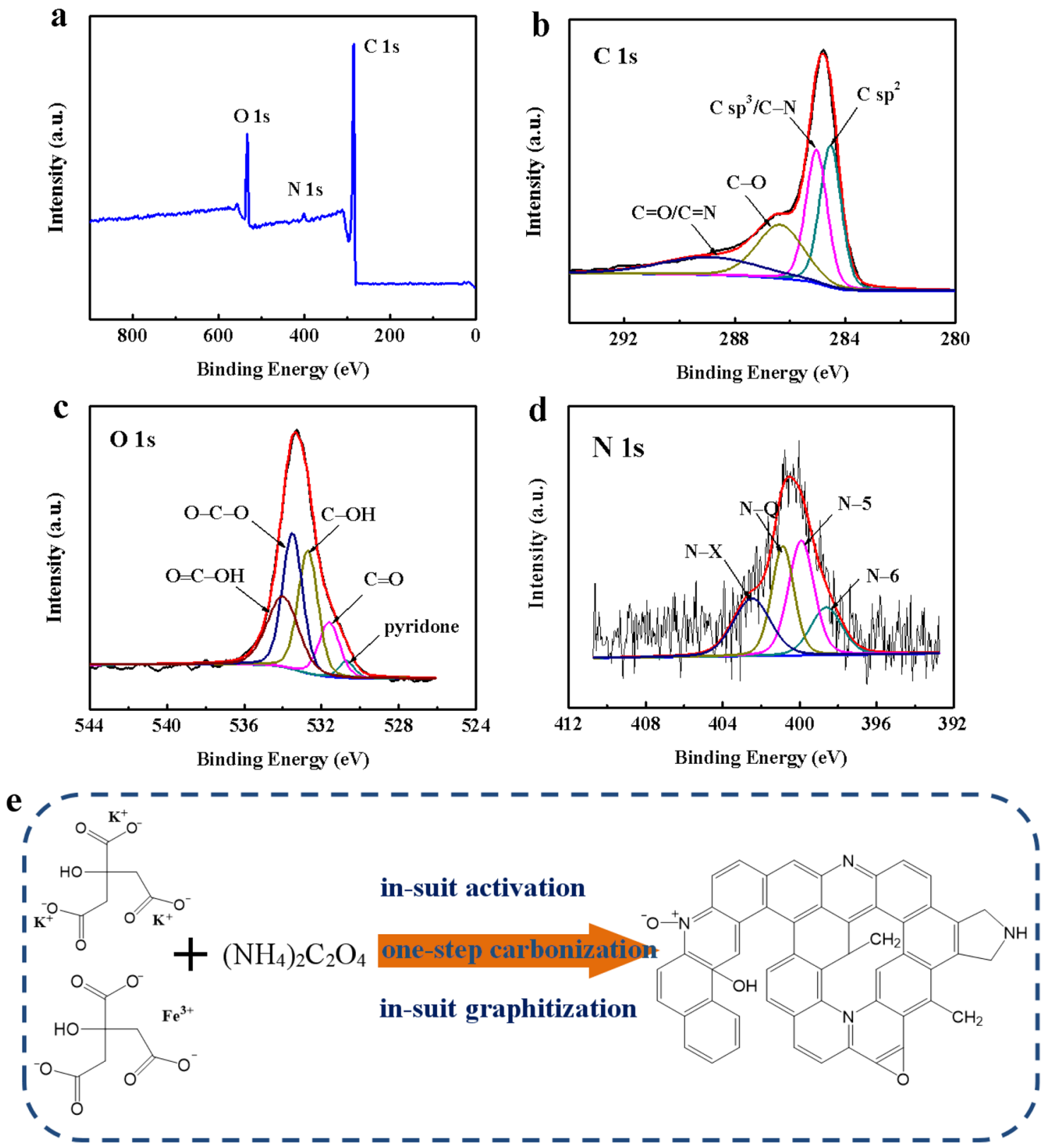

Figure 5. (a) XPS survey of HPGC-750; high resolution XPS spectra of (b) C $1 \mathrm{~s}$, (c) O $1 \mathrm{~s}$, and (d) N $1 \mathrm{~s}$ for HPGC-750; (e) synthetic route to the fabrication of HPGC- $T$ by direct pyrolysis potassium citrate and iron citrate. The synthetic route was drawn using Powerpoint 2019 (https://www.microsoft.com/zh-cn/microsoft365/get-started-with-office-2019).

can be attributed to large mesopore contribution with bigger pore size and higher graphitization degree those facilitate ion and electron transport especially at high current density. HPGC-700 possesses relatively smaller pore size of mesopores and lower graphitization degree, and exhibits a poor rate capability of $66.7 \%$.

Figure $6 \mathrm{f}$ shows the cycling stability of HPGC-750 at a scan rate of $100 \mathrm{mV} \mathrm{s}^{-1}$ for 15,000 cycles. In the initial 1750 cycles, the capacitance maintains at $99.2 \%$ of the initial capacitance, and then increases to $101.3 \%$ after 2500 cycles. The cycling-induced increase of capacitance is also reported in many references, which attributed to the penetration of electrolyte ions and in-situ activation of electrode so as to provide additional active surface area for charge storage ${ }^{29-31}$. After 2500 cycles, the electrochemical stability remains somewhat steady, and it maintains $101.5 \%$ of initial capacitance after 15,000 cycles. In comparison with the first CV curve at a scan rate of $10 \mathrm{mV} \mathrm{s}^{-1}, \mathrm{CV}$ curves after 10,000 cycles and after 15,000 cycles still maintain similar shape without obvious distortion, which demonstrates that the electrode has an excellent cycling performance.

Based on the above analysis, $750^{\circ} \mathrm{C}$ is an optimum temperature from the view of the morphologies, structures, and electrochemical performances of the carbon materials. On the basis of these, we further investigated the effects of the content of $\left(\mathrm{NH}_{4}\right)_{2} \mathrm{C}_{2} \mathrm{O}_{4}$ and the mass ratio of citrate/iron citrate on the structures and capacitive properties of the samples, denoted as $\mathrm{HPGC}_{x-y-z}$ (where $x, y, z$ refer to the mass of citrate, iron citrate, and 

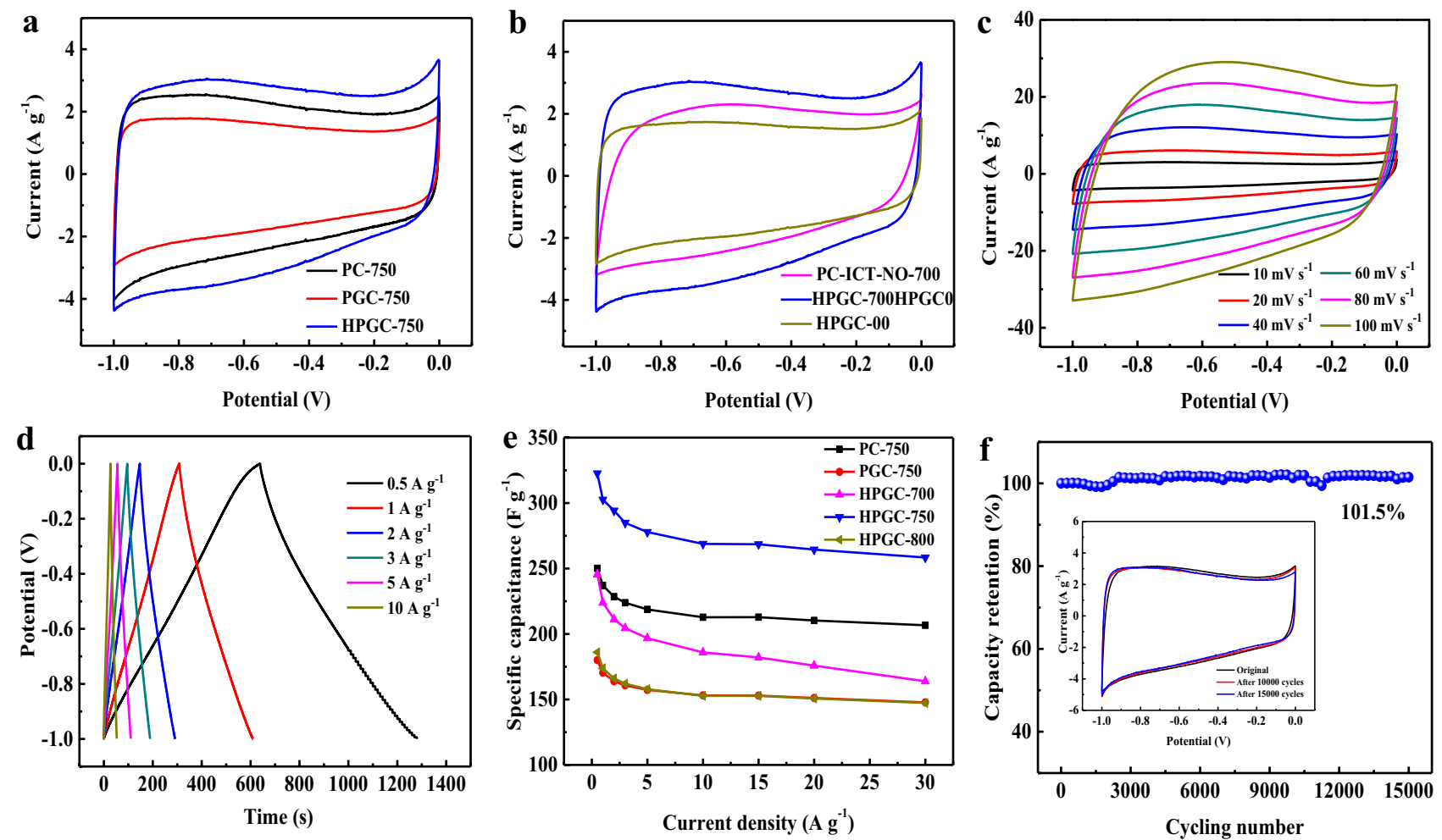

Figure 6. Electrochemical characteristics of a three-electrode system in $6 \mathrm{M} \mathrm{KOH}$ : (a) CV curves of PC-750, PGC-750, and HPGC-750 at $10 \mathrm{mV} \mathrm{s}^{-1}$; (b) CV curves of HPGC- $T$ at $10 \mathrm{mV} \mathrm{s}^{-1}$; (c) CV curves of HPGC-750 at various scan rates from 10 to $100 \mathrm{mV} \mathrm{s}^{-1}$; (d) GCD curves of HPGC-750 under various current densities; (e) specific capacitances of all electrodes as a function of current density; (f) cycling stability of HPGC-750 for 15,000 cycles measured at $100 \mathrm{mV} \mathrm{s}^{-1}$ with inset showing $\mathrm{CV}$ curves at $10 \mathrm{mV} \mathrm{s}^{-1}$.

$\left(\mathrm{NH}_{4}\right)_{2} \mathrm{C}_{2} \mathrm{O}_{4}$, respectively). Figure $\mathrm{S} 2$ displays the morphologies and structures of $\mathrm{HPGC}_{x-y-z}$. HPGC $\mathrm{H}_{3-1.5-6}$ shows little macropores (Figure S2a), and HPGC $3-1.5-10$ (Figure S2b) maintains 3D honeycomb framework. As for $\mathrm{HPGC}_{2-2.5-8}$ (Figure S2c) and HPGC $\mathrm{H}_{3-5-1-8}$ (Figure S2d), the honeycomb structure is disappeared. With different mass ratio of potassium citrate/iron citrate/ $\left(\mathrm{NH}_{4}\right)_{2} \mathrm{C}_{2} \mathrm{O}_{4}, \mathrm{HPGC}_{x-y-z}$ exhibits tunable $S_{\mathrm{BET}}$ and pore size distribution (Figure S3, Table S1). The pore sizes of all HPGC ${ }_{x-y-z}$ are mainly around 1.27 and $2.51 \mathrm{~nm}$. The $S_{\text {BET }}$ of HPGC $C_{3-1.5-z}$ decreases with increased content of $\left(\mathrm{NH}_{4}\right)_{2} \mathrm{C}_{2} \mathrm{O}_{4}$, while excessive $\left(\mathrm{NH}_{4}\right)_{2} \mathrm{C}_{2} \mathrm{O}_{4}$ results in an increased $S_{\text {BET }}$. HPGC $2-2.5-8$ has a lower $S_{\text {BET }}\left(1911 \mathrm{~m}^{2} \mathrm{~g}^{-1}\right)$ than that of $\mathrm{HPGC}_{3-1.5-8}$ due to insufficient chemical activation. But when the mass ratio of potassium citrate/iron citrate increased to $3.5: 1$, the $S_{\mathrm{BET}}$ of $\mathrm{HPGC}_{3.5-1-8}$ $\left(2125.7 \mathrm{~m}^{2} \mathrm{~g}^{-1}\right)$ decreases, probably caused by the excessive activation effect of potassium citrate. Figure $\mathrm{S} 4$ displays the electrochemical performances of all $\mathrm{HPGC}_{x-y-z}$ electrodes. When the mass ratio of potassium citrate/ iron citrate/ $\left(\mathrm{NH}_{4}\right)_{2} \mathrm{C}_{2} \mathrm{O}_{4}$ is 3:1.5:8, the carbon electrode possesses optimal capacitive performances, although its $S_{\mathrm{BET}}$ is not largest, indicating that the $S_{\mathrm{BET}}$ is not completely directly proportional to capacitance.

With 3D hierarchical porous texture and localized graphitic structure, CV curves of symmetric supercapacitor HPGC-750//HPGC-750 performed in $6 \mathrm{M} \mathrm{KOH}$ show rectangular shapes at various scan rates (Fig. 7a). The rectangular nature even at a higher scan rate of $200 \mathrm{mV} \mathrm{s}^{-1}$ is related to the presence of mesopores. All the GCD curves in Fig. 7b show regular symmetric triangle, which again confirms the double-layer formation at the electrode-electrolyte interface. The maximum specific capacitance for a single electrode calculated from GCD curves is $245.1 \mathrm{~F} \mathrm{~g}^{-1}$ at $0.5 \mathrm{~A} \mathrm{~g}^{-1}$ and it retains $201.6 \mathrm{~F} \mathrm{~g}^{-1}$ at $10 \mathrm{~A} \mathrm{~g}^{-1}$, corresponding to $82.2 \%$ capacitance retention.

The symmetric supercapacitor HPGC-750//HPGC-750 was also tested in $1 \mathrm{M} \mathrm{Na}_{2} \mathrm{SO}_{4}$, owing to its lower $\mathrm{H}^{+}$and $\mathrm{OH}^{-}$, which allows it providing a larger operating voltage. Figure $7 \mathrm{c}$ shows the CV curves of HPGC750//HPGC-750 at $40 \mathrm{mV} \mathrm{s}^{-1}$ within different potential windows, and they present well reversible cycle even at a potential window of $0-1.8 \mathrm{~V}$. The rectangle-like CV curves (Fig. $7 \mathrm{~d}$ ) and symmetrical GCD curves (Fig. 7e) within the voltage windows $0-1.8 \mathrm{~V}$ further demonstrate excellent rate capability. In $1 \mathrm{M} \mathrm{Et}_{4} \mathrm{NBF}_{4} / \mathrm{AN}$, the rectangular nature of CV curves (Figure S5a) and the linear and symmetrical characteristics of GCD curves at various current densities (Figure S5b) further reveal the electrical double-layer capacitance behavior. The Ragone plots in Fig. $7 \mathrm{f}$ show that symmetric supercapacitor HPGC-750//HPGC-750 has an excellent energy density of $21.25 \mathrm{~W} \mathrm{~h} \mathrm{~kg}^{-1}$ at $456.8 \mathrm{~W} \mathrm{~kg}^{-1}$ in $1 \mathrm{M} \mathrm{Na}_{2} \mathrm{SO}_{4}$ electrolyte, and it still retains $14.4 \mathrm{~W} \mathrm{~h} \mathrm{~kg}^{-1}$ at a high power density of $39,875.6 \mathrm{~W} \mathrm{~kg}^{-1}$. In $6 \mathrm{M} \mathrm{KOH}$ electrolyte, the energy density is $8.5 \mathrm{~W} \mathrm{~h} \mathrm{~kg}^{-1}$ at a power density of $253.0 \mathrm{~W} \mathrm{~kg}^{-1}$. Due to large potential window, the supercapacitor can achieve a high energy density of $32.3 \mathrm{~W} \mathrm{~h} \mathrm{~kg}^{-1}$ at a power density of $203.0 \mathrm{~W} \mathrm{~kg}^{-1}$ in $1 \mathrm{M} \mathrm{Et}_{4} \mathrm{NBF}_{4} / \mathrm{AN}$. The energy and power values are comparable or even superior to those of the previously reported carbon materials ${ }^{32-37}$. This is attributed to the honeycomb-like graphitic carbon 

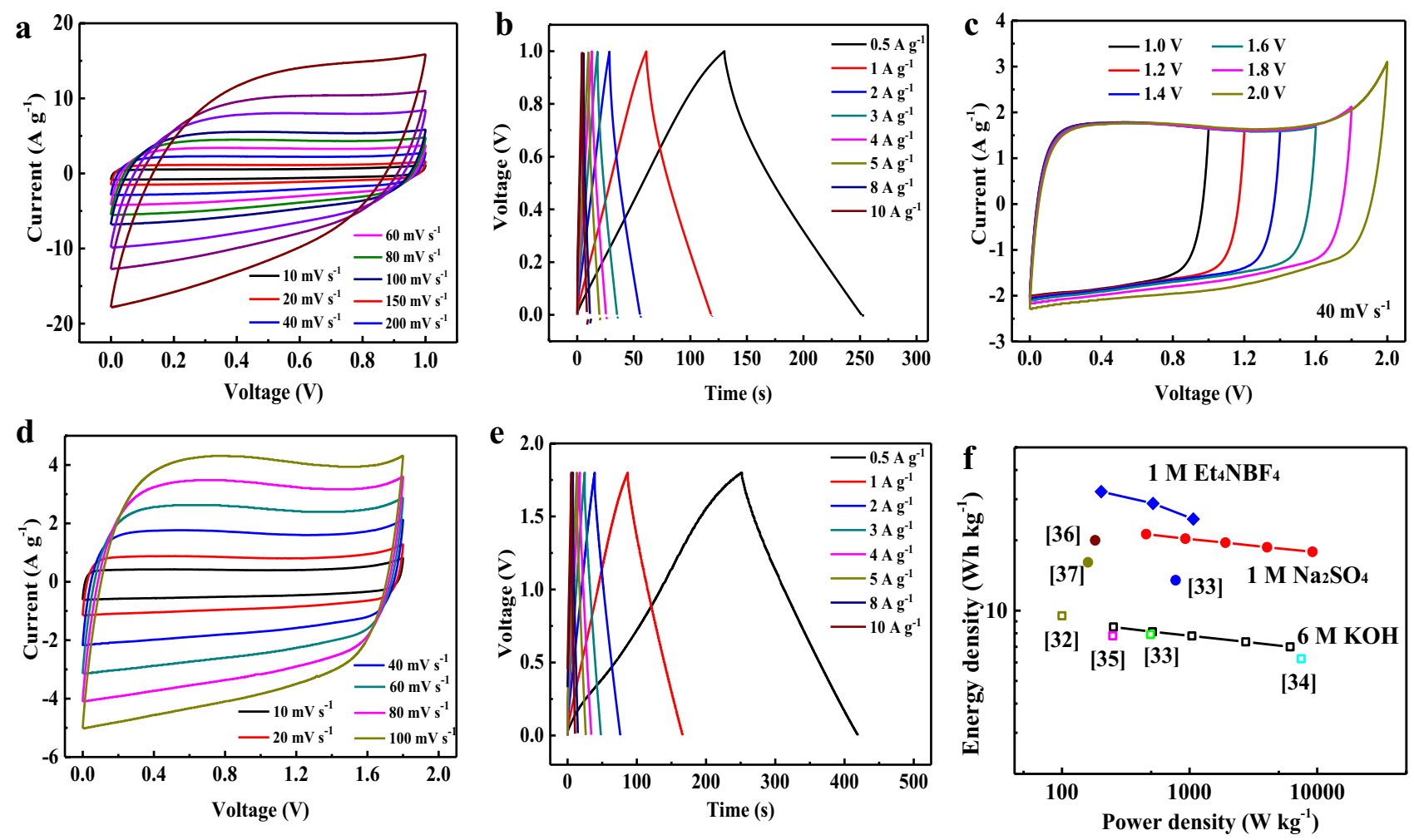

Figure 7. Electrochemical characteristics of HPGC-750 symmetric supercapacitor: (a) CV curves at various scan rates in $6 \mathrm{M} \mathrm{KOH}$; (b) GCD curves at various current densities in $6 \mathrm{M} \mathrm{KOH}$; (c) CV curves tested in different potential windows at $40 \mathrm{mV} \mathrm{s}^{-1}$ in $1 \mathrm{M} \mathrm{Na}_{2} \mathrm{SO}_{4}$; (d) $\mathrm{CV}$ curves at different scan rates in a potential window of $1.8 \mathrm{~V}$ in $1 \mathrm{M} \mathrm{Na}_{2} \mathrm{SO}_{4}$; (e) GCD curves at different current densities in $1 \mathrm{M} \mathrm{Na}_{2} \mathrm{SO}_{4}$; (f) Ragone plots of HPGC-750//HPGC-750 supercapacitor and performances comparison with other carbon-based symmetric supercapacitors (circle: $6 \mathrm{M} \mathrm{KOH}$ electrolyte, and sphere: $1 \mathrm{M} \mathrm{Na}_{2} \mathrm{SO}_{4}$ electrolyte).
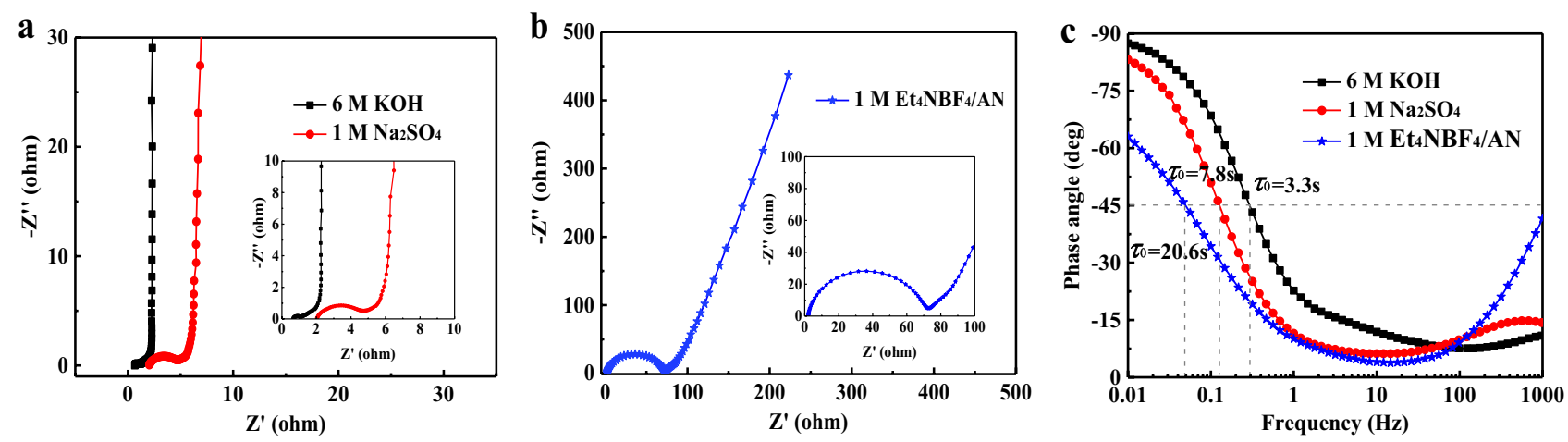

Figure 8. (a) Nyquist plots of HPGC-750 symmetric supercapacitors in $6 \mathrm{M} \mathrm{KOH}$ and $1 \mathrm{M} \mathrm{Na}_{2} \mathrm{SO}_{4}$, (b) Nyquist plots of HPGC-750 symmetric supercapacitors in $1 \mathrm{M} \mathrm{Et}_{4} \mathrm{NBF}_{4} / \mathrm{AN}$, and (c) Bode phase angle plots of HPGC750 symmetric supercapacitors in different electrolytes.

skeleton benefiting the mass transport and electron transfer through the open pore channels and interconnected carbon network.

Electrochemical impedance spectroscopy was also measured to evaluate the ion and electron transport kinetics in different electrolytes. Figure 8a shows the Nyquist plots of HPGC-750 supercapacitors in $6 \mathrm{M} \mathrm{KOH}$ and $1 \mathrm{M} \mathrm{Na}_{2} \mathrm{SO}_{4}$ and Fig. $8 \mathrm{~b}$ shows the Nyquist plots in $1 \mathrm{M} \mathrm{Et}_{4} \mathrm{NBF}_{4} / \mathrm{AN}$. The vertical nature of curves in the low frequency region indicates nearly ideal capacitive performance. The semicircle in high frequency region is related to charge transfer resistance $\left(R_{\mathrm{ct}}\right)$. It is observed that the diameters of the semicircles for aqueous electrolytes are much smaller than that for organic electrolyte. The value of equivalent series resistance $\left(R_{\mathrm{s}}\right)$ for $\mathrm{KOH}$ electrolyte is calculated to be $0.60 \Omega$, and it is $2.07 \Omega$ for $1 \mathrm{M} \mathrm{Na}_{2} \mathrm{SO}_{4}, 2.14 \Omega$ for $1 \mathrm{M} \mathrm{Et}_{4} \mathrm{NBF}_{4} / \mathrm{AN}$. The smaller $R_{\mathrm{s}}$ and $R_{\mathrm{ct}}$ for aqueous electrolytes than that for organic electrolyte could be ascribed to high conductivity, small ion size, and quick ionic mobility of aqueous electrolyte ${ }^{38}$. Figure $8 \mathrm{c}$ shows the Bode phase angle plots. The large phase 
angles $\left(-87.2^{\circ}\right.$ for $\mathrm{KOH}$ and $-82.5^{\circ}$ for $\left.\mathrm{Na}_{2} \mathrm{SO}_{4}\right)$ at low frequency indicate mainly electrical double-layer capacitance. The relaxation time constants $\left(\tau_{0}=1 / f\right.$, at the phase angle of $\left.-45^{\circ}\right)$ are $7.8 \mathrm{~s}$ for $\mathrm{KOH}$ and $3.3 \mathrm{~s}$ for $\mathrm{Na}_{2} \mathrm{SO}_{4}$ electrolyte. The fast frequency response indicates the fast charge-discharge rate. However, for $1 \mathrm{M} \mathrm{Et}_{4} \mathrm{NBF}_{4} / \mathrm{AN}$ electrolyte, the relaxation time constant is $20.6 \mathrm{~s}$ because of larger size of ion and higher electrolyte resistance of organic electrolyte.

\section{Conclusion}

In summary, hierarchical porous graphitic carbon with interconnected framework has been successfully synthesized by in situ activation-graphitization method through only one-step pyrolysis of potassium citrate, ferric citrate, and $\left(\mathrm{NH}_{4}\right)_{2} \mathrm{C}_{2} \mathrm{O}_{4}$. The obtained HPGC-750 balances the relationship between pore structure and electrical conductivity. It possesses favorable characteristics, such as high $S_{\mathrm{BET}}$ of $2973.3 \mathrm{~m}^{2} \mathrm{~g}^{-1}$, good conductivity, and hierarchical porous structure facilitating ion transportation and accommodation in electrodes. Such unique architecture endows HPGC-750 with excellent electrochemical performances: a high capacitance of $322.6 \mathrm{~F} \mathrm{~g}^{-1}$ at $0.5 \mathrm{~A} \mathrm{~g}^{-1}$, good rate capability with $258.4 \mathrm{~F} \mathrm{~g}^{-1}$ at $30 \mathrm{~A} \mathrm{~g}^{-1}$, and an outstanding cycle stability (no loss after 15,000 cycles). Supercapacitor prepared with HPGC-750 shows a high energy density $21.3 \mathrm{~W} \mathrm{~h} \mathrm{~kg}^{-1}$ at a high power density of $456.7 \mathrm{~W} \mathrm{~kg}^{-1}$ in $1 \mathrm{M} \mathrm{Na}_{2} \mathrm{SO}_{4}$ electrolyte. This study provides a promising strategy to develop hierarchical porous graphitic carbon for high-performance of supercapacitors and other energy researches such as fuel cell, catalysis, and so on.

\section{Methods}

Materials. Iron citrate $\left(\mathrm{FeC}_{6} \mathrm{H}_{5} \mathrm{O}_{7} \cdot 5 \mathrm{H}_{2} \mathrm{O}\right)$ was provided by Aladdin Industrial Co., Ltd. Potassium citrate tribasic monohydrate $\left(\mathrm{C}_{6} \mathrm{H}_{5} \mathrm{~K}_{3} \mathrm{O}_{7} \cdot \mathrm{H}_{2} \mathrm{O}\right)$ and diammonium oxalate monohydrate $\left[\left(\mathrm{NH}_{4}\right)_{2} \mathrm{C}_{2} \mathrm{O}_{4} \cdot \mathrm{H}_{2} \mathrm{O}\right]$ were purchased from Tianjin Tianli Chemical Reagent Co., Ltd. Potassium hydroxide $(\mathrm{KOH})$, sodium sulfate $\left(\mathrm{Na}_{2} \mathrm{SO}_{4}\right)$ and hydrochloric acid $(\mathrm{HCl})$ were provided by Tianjin Fengchuan Chemical Reagent Technologies Co. Ltd. All the chemical reagents were used as received. Deionized water was used throughout the experiments.

Preparation of materials. In a typical synthesis, $3 \mathrm{~g}$ potassium citrate tribasic monohydrate, $1.5 \mathrm{~g}$ iron citrate, and $8 \mathrm{~g}$ diammonium oxalate monohydrate were grinded homogeneously to achieve a sufficient contact. Subsequently, the mixture was carbonized in a $\mathrm{N}_{2}$ atmosphere at high temperatures $\left(700,750\right.$, and $800{ }^{\circ} \mathrm{C}$ ) for $2 \mathrm{~h}$ at a heating rate of $5{ }^{\circ} \mathrm{C} \mathrm{min}^{-1}$. The calcined products were treated with $3 \mathrm{M} \mathrm{HCl}$ solution and then washed with deionized water several times. After dried at $80^{\circ} \mathrm{C}$, the final product HPGC- $T$ was obtained (where $T$ represents carbonization temperature).

For comparison, the sample synthesized by solely pyrolysis potassium citrate at $750{ }^{\circ} \mathrm{C}$ was denoted as PC-750. To evaluate the effect of $\left(\mathrm{NH}_{4}\right)_{2} \mathrm{C}_{2} \mathrm{O}_{4}$ on the structure of the resultant carbon materials, synthesis without $\left(\mathrm{NH}_{4}\right)_{2} \mathrm{C}_{2} \mathrm{O}_{4}$ was also performed, and the resultant sample was labeled as PGC-750.

Materials characterization. Scanning electron microscopy (SEM, JSM-6510F) was conducted to investigate and morphologies and structures of the samples. Transmission electron microscopy (TEM) was taken using FEI-G2F20. X-ray diffraction (XRD) patterns were obtained by Miniflex 600 diffractometer. Raman spectra were measured by using a Jobin-Yvon, HR 800 spectrometer. The $\mathrm{N}_{2}$ adsorption-desorption isotherms were obtained by using Micromeritics ASAP 2460 instrument ${ }^{39}$. Surface chemical composition of the sample was investigated by X-ray photoelectron spectroscopy (XPS, ESCALAB 250) and fourier transformation infrared spectroscopy (FTIR, Bruker Tensor 27).

Electrochemical measurement. The electrochemical performances of samples were evaluated by cyclic voltammetry $(\mathrm{CV})$, galvanostatic charge-discharge (GCD) and electrochemical impedance spectroscopy (EIS) through a CHI760e electrochemical workstation. Active carbon material (2.4 mg, $80 \mathrm{wt} \%$ ), acetylene black $(10 \mathrm{wt} \%)$, and polytetrafluoroethylene $(10 \mathrm{wt} \%)$ were mixed and coated on a nickel foam to prepare a working electrode. In a three-electrode system, $\mathrm{Hg} / \mathrm{HgO}$ and $\mathrm{Pt}$ foil electrodes were used as the reference electrode and the counter electrode, respectively. The electrolyte was $6 \mathrm{M} \mathrm{KOH}$ solution. The specific capacitance $C\left(\mathrm{~F} \mathrm{~g} \mathrm{~g}^{-1}\right)$ in the three-electrode system can be obtained by following equation:

$$
C=I \cdot \Delta t /(m \cdot \Delta V)
$$

where $I, \Delta t, m$, and $\Delta V$ are the discharge current (A), the discharge time (s), the mass of active material (g), and the potential window $(\mathrm{V})$, respectively.

In two-electrode system, the cell consists of two symmetric electrodes with equal mass were separated by a polypropylene membrane using $6 \mathrm{M} \mathrm{KOH}, 1 \mathrm{M} \mathrm{Na}_{2} \mathrm{SO}_{4}$, or $1 \mathrm{M} \mathrm{Et}_{4} \mathrm{NBF}_{4} / \mathrm{AN}$ electrolyte. The specific capacitance $C_{\text {sp }}\left(\mathrm{F} \mathrm{g}^{-1}\right)$ for a single electrode, energy density $E\left(\mathrm{~W} \mathrm{~h} \mathrm{Kg}{ }^{-1}\right)$, and power density $P\left(\mathrm{~W} \mathrm{Kg}^{-1}\right)$ of supercapacitor were calculated according to the following Eqs. (2)-(4):

$$
\begin{gathered}
C_{\mathrm{sp}}=4 I \cdot \Delta t /(m \cdot \Delta V) \\
E=C_{\mathrm{sp}} \cdot V^{2} / 8 \\
P=E / \Delta t
\end{gathered}
$$

where $m$ is the total mass of active materials for two electrodes $(\mathrm{g}), V$ is the maximum discharging potential $(\mathrm{V})^{39}$. 
Received: 10 December 2020; Accepted: 22 February 2021

Published online: 25 March 2021

\section{References}

1. Wang, J., Zhang, X., Li, Z., Ma, Y. \& Ma, L. Recent progress of biomass-derived carbon materials for supercapacitors. J. Power Sources 451, 227794. https://doi.org/10.1016/j.jpowsour.2020.227794 (2020).

2. Zou, L. et al. A honeycomb-like bulk superstructure of carbon nanosheets for electrocatalysis and energy storage. Angew. Chem. Int. Ed. Engl. 59, 1-7. https://doi.org/10.1002/anie.202004737 (2020).

3. Zhu, Q. et al. A new view of supercapacitors: Integrated supercapacitors. Adv. Energy Mater. 9, 1901081. https://doi.org/10.1002/ aenm.201901081 (2019).

4. Shang, Y., Ma, S., Wei, Y., Yang, H. \& Xu, Z. Flower-like ternary metal of Ni-Co-Mn hydroxide combined with carbon nanotube for supercapacitor. Ionics 26, 3609-3619. https://doi.org/10.1007/s11581-020-03496-7 (2020).

5. Chen, Z. et al. Excellent electrochemical performance of potassium ion capacitor achieved by a high nitrogen doped activated carbon. J. Electrochem. Soc. 167, 050506. https://doi.org/10.1149/1945-7111/ab6a84 (2020).

6. Chen, Y. et al. Preparation of nitrogen and sulfur co-doped graphene aerogel with hierarchical porous structure using ionic liquid precursor for high-performance supercapacitor. Ionics 25, 2781-2789. https://doi.org/10.1007/s11581-018-2785-y (2018).

7. Tian, W. et al. Porous carbons: Structure-oriented design and versatile applications. Adv. Funct. Mater. 1909265. https://doi.org/ 10.1002/adfm.201909265 (2020).

8. Chen, Q. et al. Biomass-derived porous graphitic carbon materials for energy and environmental applications. J. Mater. Chem. A 8, 5773-5811. https://doi.org/10.1039/c9ta11618d (2020).

9. Zhang, Y. et al. Biomass organs control the porosity of their pyrolyzed carbon. Adv. Funct. Mater. 27, 1604687. https://doi.org/10. 1002/adfm.201604687 (2017).

10. Chang, C. et al. Fabrication of hierarchical porous carbon frameworks from metal-iIon-assisted step-activation of biomass for supercapacitors with ultrahigh capacitance. ACS Sustain. Chem. Eng. 7, 10763-10772. https://doi.org/10.1021/acssuschemeng. 9b01455 (2019).

11. Hou, J., Cao, C., Idrees, F. \& Ma, X. Hierarchical porous nitrogen-doped carbon nanosheets derived from silk for ultrahigh-capacity battery anodes and supercapacitors. ACS Nano 9, 2556-2564 (2015)

12. Chang, B. et al. Graphitized hierarchical porous carbon nanospheres: simultaneous activation/graphitization and superior supercapacitance performance. J. Mater. Chem. A 3, 9565-9577. https://doi.org/10.1039/c5ta00867k (2015).

13. He, Y. et al. Porous carbon nanosheets: Synthetic strategies and electrochemical energy related applications. Nano Today 24, 103-119. https://doi.org/10.1016/j.nantod.2018.12.004 (2019).

14. Xue, D. et al. Template-free, self-doped approach to porous carbon spheres with high N/O contents for high-performance supercapacitors. ACS Sustain. Chem. Eng. 7, 7024-7034. https://doi.org/10.1021/acssuschemeng.8b06774 (2019).

15. Sun, X. et al. Activation of graphene aerogel with phosphoric acid for enhanced electrocapacitive performance. Carbon $92,1-10$ (2015).

16. Guan, L. et al. Green and scalable synthesis of porous carbon nanosheet-assembled hierarchical architectures for robust capacitive energy harvesting. Carbon 152, 537-544. https://doi.org/10.1016/j.carbon.2019.06.059 (2019).

17. Zhang, X. et al. Porous graphitic carbon microtubes derived from willow catkins as a substrate of $\mathrm{MnO}_{2}$ for supercapacitors. J. Power Sources 344, 176-184. https://doi.org/10.1016/j.jpowsour.2017.01.107 (2017).

18. Sevilla, M. \& Fuertes, A. B. Direct synthesis of highly porous interconnected carbon nanosheets and their application as highperformance supercapacitors. ACS Nano 8, 5069-5078 (2014).

19. Zhu, J. et al. Ferric citrate-derived N-doped hierarchical porous carbons for oxygen reduction reaction and electrochemical supercapacitors. Carbon 115, 1-10. https://doi.org/10.1016/j.carbon.2016.12.084 (2017).

20. Wang, K., Zhang, Z., Sun, Q., Wang, P. \& Li, Y. Durian shell-derived N, O, P-doped activated porous carbon materials and their electrochemical performance in supercapacitor. J. Mater, Sci. 55, 10142-10154. https://doi.org/10.1007/s10853-020-04740-1 (2020).

21. Zhang, X. et al. Strategy for preparing porous graphitic carbon for supercapacitor: Balance on porous structure and graphitization degree. J. Electrochem. Soc. 165, A2084-A2092. https://doi.org/10.1149/2.0491910jes (2018).

22. Sun, N. et al. Hierarchical porous carbon materials derived from kelp for superior capacitive applications. ACS Sustain. Chem. Eng. 7, 8735-8743. https://doi.org/10.1021/acssuschemeng.9b00635 (2019).

23. Chang, B. et al. N-rich porous carbons with a high graphitization degree and multiscale pore network for boosting high-rate supercapacitor with ultrafast charging. Chem. Eng. J. 350, 585-598. https://doi.org/10.1016/j.cej.2018.06.013 (2018).

24. Wang, H. et al. Interconnected carbon nanosheets derived from hemp for ultrafast supercapacitors with high energy. ACS Nano 7, 5131-5141 (2013)

25. Wu, X. et al. Biomass-derived sponge-like carbonaceous hydrogels and aerogels for supercapacitors. ACS Nano 7, 3589-3597 (2013).

26. Kumar, A., Das, D., Sarkar, D., Patil, S. \& Shukla, A. Supercapacitors with prussian blue derived carbon encapsulated Fe/Fe3C nanocomposites. J. Electrochem. Soc. 167, 060529. https://doi.org/10.1149/1945-7111/ab838f (2020).

27. Li, B. et al. Nitrogen doped and hierarchically porous carbons derived from chitosan hydrogel via rapid microwave carbonization for high-performance supercapacitors. Carbon 122, 592-603. https://doi.org/10.1016/j.carbon.2017.07.009 (2017).

28. Chen, Z. et al. High-performance supercapacitors based on hierarchically porous graphite particles. Adv. Energy Mater. 1, 551-556. https://doi.org/10.1002/aenm.201100114 (2011).

29. Yoon, Y. et al. Anti-solvent derived non-stacked reduced graphene oxide for high performance supercapacitors. Adv. Mater. 25, 4437-4444. https://doi.org/10.1002/adma.201301230 (2013).

30. Ouyang, T. et al. Molten salt synthesis of nitrogen doped porous carbon: A new preparation methodology for high-volumetric capacitance electrode materials. J. Mater. Chem. A 4, 9832-9843. https://doi.org/10.1039/c6ta02673g (2016).

31. Deng, J. et al. Highly active and durable non-precious-metal catalysts encapsulated in carbon nanotubes for hydrogen evolution reaction. Energy Environ. Sci. 7, 1919-1923. https://doi.org/10.1039/c4ee00370e (2014).

32. Sun, Y. et al. Biomass-derived porous carbon electrodes for high-performance supercapacitors. J. Mater. Sci. 55, 5166-5176. https:// doi.org/10.1007/s10853-019-04343-5 (2020).

33. Ma, F. et al. Construction of 3D nanostructure hierarchical porous graphitic carbons by charge-induced self-assembly and nanocrystal-assisted catalytic graphitization for supercapacitors. Chem. Commun. 52, 6673-6676. https://doi.org/10.1039/c6cc0 $2147 \mathrm{f}(2016)$.

34. Qian, W., Zhu, J., Zhang, Y., Wu, X. \& Yan, F. Condiment-derived 3D architecture porous carbon for electrochemical supercapacitors. Small 11, 4959-4969. https://doi.org/10.1002/smll.201500859 (2015).

35. Wei, T. et al. A one-step moderate-explosion assisted carbonization strategy to sulfur and nitrogen dual-doped porous carbon nanosheets derived from camellia petals for energy storage. J. Power Sources 331, 373-381. https://doi.org/10.1016/j.jpowsour. 2016.09.053 (2016). 
36. Feng, H. et al. Hierarchical structured carbon derived from bagasse wastes: A simple and efficient synthesis route and its improved electrochemical properties for high-performance supercapacitors. J. Power Sources 302, 164-173. https://doi.org/10.1016/j.jpows our.2015.10.063 (2016).

37. Su, X. et al. Three-dimensional porous activated carbon derived from loofah sponge biomass for supercapacitor applications. Appl. Surf. Sci. 436, 327-336. https://doi.org/10.1016/j.apsusc.2017.11.249 (2018).

38. Zhang, X. et al. Direct synthesis of porous graphitic carbon sheets grafted on carbon fibers for high-performance supercapacitors. J. Mater. Chem. A 7, 3298-3306. https://doi.org/10.1039/c8ta11844b (2019).

39. Zhang, X. et al. Design and structure optimization of 3D porous graphitic carbon nanosheets for high-performance supercapacitor. Microporous Mesoporous Mater. 309, 110580. https://doi.org/10.1016/j.micromeso.2020.110580 (2020).

\section{Acknowledgements}

All authors are very grateful for the financial support of the Natural Science Foundation of Shanxi Province (No. 201901D111215), the Doctor Funds of Taiyuan University of Science and Technology (No. 20192054).

\section{Author contributions}

Y.Z. prepared resources and wrote the main manuscript text. X.Z. reviewed the manuscript.

\section{Competing interests}

The authors declare no competing interests.

\section{Additional information}

Supplementary Information The online version contains supplementary material available at https://doi.org/ 10.1038/s41598-021-85661-0.

Correspondence and requests for materials should be addressed to Y.Z. or X.Z.

Reprints and permissions information is available at www.nature.com/reprints.

Publisher's note Springer Nature remains neutral with regard to jurisdictional claims in published maps and institutional affiliations.

(c) (i) Open Access This article is licensed under a Creative Commons Attribution 4.0 International

License, which permits use, sharing, adaptation, distribution and reproduction in any medium or format, as long as you give appropriate credit to the original author(s) and the source, provide a link to the Creative Commons licence, and indicate if changes were made. The images or other third party material in this article are included in the article's Creative Commons licence, unless indicated otherwise in a credit line to the material. If material is not included in the article's Creative Commons licence and your intended use is not permitted by statutory regulation or exceeds the permitted use, you will need to obtain permission directly from the copyright holder. To view a copy of this licence, visit http://creativecommons.org/licenses/by/4.0/.

(C) The Author(s) 2021 